\title{
Effect of Aerobic Exercise on Protein Expression in Muscle of Obese Mexican Adolescents: A Proteomic and Bioinformatic Analysis
}

\author{
Maciste H. Macías-Cervantes ${ }^{1}$, Juan M. Guzmán-Flores ${ }^{1}$, Katya Vargas-0rtiz ${ }^{1}$, \\ Francisco J. Díaz-Cisneros ${ }^{2}$, Joel Ramírez-Emiliano1, Victoriano Pérez-Vázquez1 ${ }^{*}$ \\ ${ }^{1}$ Departmento de Ciencias Médicas, División de Ciencias de la Salud, Universidad de Guanajuato, León, México \\ ${ }^{2}$ Departmento de Ciencias Aplicadas al Trabajo, División de Ciencias de la Salud, Universidad de Guanajuato, \\ León, México \\ Email: vpvazquez@ugto.mx
}

Received 8 January 2014; revised 8 February 2014; accepted 15 February 2014

Copyright (C) 2014 by authors and Scientific Research Publishing Inc.

This work is licensed under the Creative Commons Attribution International License (CC BY). http://creativecommons.org/licenses/by/4.0/

c) (i) Open Access

\section{Abstract}

The beneficial effects of exercise have been recognized for many years yet the molecular mechanisms by which exercise show benefits on health are still elusive. A combination of experimental and bioinformatics approaches can be an invaluable tool to increase the cellular understanding of the molecular mechanisms that underlie the aerobic exercise in obese adolescents. Muscle skeletal proteins were separated by 2D-PAGE and changes in protein expression were revealed by ImageMaster 2D Platinum analysis software. Proteins with expression changes after aerobic exercise were identified by comparison with 2D maps from SWISS-2DPAGE and interactions of proteins were analyzed with STRING and DAVID databases. After aerobic exercise, all participants decreased glucose, insulin, total cholesterol, body mass index and waist circumference. Proteomic differential analysis revealed 10 overexpressed proteins after aerobic training, which correspond to carbonic anhydrase III, beta enolase, creatine kinase, ATP synthase beta subunit, aldolase A, glyceraldehyde-3-phosphate dehydrogenase, triosephosphate isomerase, pyruvate kinase, lactate dehydrogenase and adenylate kinase. Exercise increased glycolysis and oxidative phosphorylation pathways, which is likely to be regulated by ubiquitin c protein. In conclusion, our analysis suggested that obese adolescents show changes in their body mass index, waist circumference and serum glucose after aerobic exercise through improved protein expression patterns that aid, especially, glucose metabolism and increase the oxidative phosphorylation. The most likely explanation for the observed pattern is that ubiquitin c protein keeps the glycolytic enzymes bound

\footnotetext{
*Corresponding author.
} 
within skeletal muscle, obtaining a non-degradative role in cell signaling.

Keywords

Glycolysis, Oxidative Phosphorylation, Ubiquitin C Protein, Proteomics, Exercise

\section{Introduction}

Over the past decade or so, changes in lifestyle have resulted in decreased physical activity and increased obesity [1]. Obese patients have often been diagnosed with "muscle skeletal inflexibility", characterized by lipid toxicity and a tendency to develop insulin resistance [2]. Patients with insulin resistance have alterations in metabolic pathways such as oxidative phosphorylation and AMP protein kinase dependent pathways [3]. In addition, there is enough background literature to show the benefits of exercise in healthy people [4], diabetic patients [5], postmenopausal women [6], obese adolescents [7] and children with insulin resistance [8]. Metabolic improvements are explained partially due to changes in skeletal muscle system [9]. Skeletal muscle is an important metabolic tissue because during exercise it metabolizes carbohydrates and lipids in the mitochondrion.

Many studies have demonstrated biochemical changes after exercise [10]-[12]. However, an integrative study of multiple changes in proteins is necessary in order to increase understanding of physiological pathways that improve metabolic state through exercise. In the past decade, proteomic profiling using mass spectrometry has undergone a remarkable transformation from a highly specialized sub-discipline to a much more accessible technique for the non-specialist and clinical research scientist [13]. Proteomics is a powerful tool that helps us to study protein profile expression; in one experiment we might observe hundreds or thousands of protein changes and built interaction networks. In order to increase understanding of the molecular mechanisms within the cell that underlie aerobic exercise and obesity in adolescents, we initiated a two-dimensional gel electrophoresisbased proteomic and computational analysis of skeletal muscle preparations from overweight adolescents.

\section{Methods}

\subsection{Subjects}

Participants were 4 male adolescents between 15 and 18 years $\left(16\right.$ years, BMI $\left.=33.81 \mathrm{Kg} / \mathrm{m}^{2}\right)$ diagnosed as obese according to the criteria of the International Obesity Task Force (IOTF) [14]. They were sedentary (defined as less than 90 min per week of regular physical activity in the last year), all were without apparent diseases or muscle alterations. Participants who missed two consecutive weeks of training or failed to meet $80 \%$ attendance at scheduled meetings were excluded from the study. The procedures were approved by the Ethics Committee of the University of Guanajuato and written informed consent was obtained from the parents and participants.

Initial screening was conducted by medical history and lifestyle information including eating and physical activity habits. Blood pressure was measured in duplicate by the auscultatory method using a mercury sphygmomanometer (Welch Allyn Tycos, USA) following the guidelines for hypertension detection [15]. Venous blood samples were obtained at rest from the antecubital vein to measure glucose, insulin and lipid profiles; the glucose was determined by enzymatic colorimetric method, glucose oxidase/peroxidase (BioSystems, USA), the insulin level was determined by radioimmunoassay (Human Insulin Specific, MILLIPORE, USA), the lipid profile was determined by enzymatic colorimetric method (SPINREACT, Spain). Participants underwent anthropometric measurements according to ISAK Protocol (International Society for the Advancement of the Kinanthropometry). The sum of 3 skinfolds (chest, abdomen and thigh) was used to calculate body fat percentage according to Jackson and Pollock [16]. A 12 lead electrocardiogram (ECG) was obtained at rest (Burdick EK10 Milton WI, USA) in order to discard alterations or contraindications for exercise. Participants were tested using a maximal incremental exercise test on a treadmill (Track Master Research, Eastlake, OH, USA), to obtained maximal heart rate (HRM) and calculate the oxygen consumption peak $\left(\mathrm{VO}_{2 \text { peak }}\right)$. Briefly, after warming-up for $3 \mathrm{~min}$ at $2.8 \mathrm{mph}$ at a slope of $0 \%$, an exercise test was performed following the Balke protocol $(3.4 \mathrm{mph}+1 \%$ increase in slope every minute) [17]. During the test, heart rate was continuously recorded with a monitor (Polar RS400SD, Kempele Finland). $\mathrm{VO}_{2 \text { peak }}$ was defined when the subjects reached maximal fatigue, a rate of per- 
ceived exertion $>17$ or a heart rate of 190 - 210 beats/min. The $\mathrm{VO}_{2 \text { peak }}$ was calculated using the following equation according to Pollock [17]:

$$
\mathrm{VO}_{2 \text { peak }}(\mathrm{ml} / \mathrm{kg} / \mathrm{min})=0.2(\text { speed })+0.9(\text { speed })(\% \text { inclination }) \text { speed }+3.5 \text {. }
$$

The intensity of the training was prescribed according to $\mathrm{HRM}$ and $\mathrm{VO}_{2 \text { peak }}$.

\subsection{Skeletal Muscle Biopsy Technique}

Before and after a percutaneous needle muscle biopsy (approximately $200 \mathrm{mg}$ ) was obtained from the right vastus lateralis muscle under local anesthesia. Skeletal muscle samples were washed with a buffer $(20 \mathrm{mM}$ Tris/HCl pH7.8, $10 \mathrm{mM}$ EDTA, $2 \mathrm{mM}$ DTT and protease inhibitor) and stored at $-70^{\circ} \mathrm{C}$ for further analysis. The post intervention biopsies were done through adjacent incision to the baseline site, 48 or 72 hours after the last training session.

\subsection{Exercise Training}

Participants exercised 50 minutes/day for 3 days/week using a cycle ergometer (Monark 839E) or a treadmill (Track Master Research) at an intensity of $70 \%$ to $80 \%$ of maximal heart rate verified each minute with a monitor (Polar RS400SD, Kempele, Finland) under the supervision of experienced personnel. Workloads were increased as needed to maintain the prescribed exercise intensity through the study.

\subsection{Proteomic Profile}

Muscle samples with a wet weight of $100 \mathrm{mg}$ were suspended in a lysis buffer (7.0 M Urea, 2.0 M thiourea, 4\% (v/w) CHAPS, $100 \mathrm{mM}$ DTT and $30 \mathrm{mM}$ Tris Base, plus complete protease inhibitor) and homogenized using a Sample Grinding Kit (GE, Healthcare). The protein content was quantified with a 2D-Quant Kit (GE, Healthcare). An IPG-buffer $\mathrm{pH} 3$ - $10 \mathrm{NL}$ was added to the homogenates for a final concentration of $0.5 \%(\mathrm{v} / \mathrm{v})$. Protein homogenate samples, containing $50 \mu \mathrm{g}$ of protein in DeStreak rehydration solution were added to a final volume of $125 \mu \mathrm{l}$ on $7 \mathrm{~cm} 3$ - 10 Non-Linear Immobilized pH gradient strips (GE, Healthcare) and rehydrated for 16 hours, at room temperature. The first dimension was run using an Ettan IPGphor 3 unit (GE Healthcare) applying a total of $7000 \mathrm{~V}$. Prior to the second dimension, each strip was equilibrated for 10 minutes in an equilibration buffer (50 mM Tris-HCl pH 8.8, 6 M Urea, 30\% (v/v) Glycerol (87\%), 2\% (w/v) SDS, trace of Bromophenol blue and $0.5 \%$ DTT). Samples were then alkylated by further equilibration for 10 minutes in the same buffer, containing $4.5 \%(\mathrm{w} / \mathrm{v})$ iodoacetamide instead of DTT. The second dimension was conducted by loading the strips onto a $12.5 \%$ acrylamide gel using the mini-PROTEAN Tetra Cell electrophoresis apparatus (Biorad). Gels were run at $130 \mathrm{~V}$, until the blue front reached the bottom of the gel. The protein separation pattern on two dimensional gels was visualized by silver staining according to the manufacturers (GE, Healthcare). Gels were scanned in an ImageScanner III densitometer. Digital images were analyzed and compared using the ImageMaster 2D Platinum analysis software Ver 7.0 (GE Healthcare). Each experiment was done in triplicate. Once the digital image of each gel was compared against the rest, the electrophoretic entities of interest were compared against two-dimensional maps of reference from the SWISS-2DPAGE database in order to identify the proteins. Protein expressions that changed at least twice were considered.

\subsection{Caloric Intake Assessment}

Energy consumption was evaluated by 24-h recall at the beginning and the end of the study. The information analysis was performed with a computer program (Nutrikcal ${ }^{\circledR}$ VO Software) in order to get the total energy (kcal/day). Participants were advised to maintain their regular eating habits for the duration of the 12 training weeks.

\subsection{Bioinformatics Analysis}

To understand the relationship among differentially expressed proteins in skeletal muscle after aerobic training and their interaction with other proteins, we analyzed the interactome using STRING database 9.05 [18]. Analysis of differentially expressed proteins by Gene Ontology assignment was performed using DAVID v6.7 [19] [20]. Proteins were uploaded into the DAVID functional annotation tool and compared to the human proteome 
background. Enriched pathways and Gene Ontology FAT terms with a minimum of 2-fold enrichment and a Fisher's Exact test p-value $\leq 0.05$ were considered and the top Gene Ontology terms with protein change expression are reported as the proportion of genes involved relative to the total number of genes involved in the whole human genome background.

\subsection{Statistical Analysis}

The analysis of changes before and after the training period was performed by Wilcoxon tests (Statistic 6 ver. USA) $\mathrm{p} \leq 0.05$ was considered significant.

\section{Results}

Participants did not change total energy intake and increased their $\mathrm{VO}_{2 \max }(28.3$ to $30.7 \mathrm{ml} / \mathrm{Kg} / \mathrm{min}, \mathrm{p}=0.03$ ), this data shown that exercise was effectiveness. Clinical characteristics are shown in Table 1. All participants decreased glucose, insulin, total cholesterol, BMI and waist circumference. Proteomic differential analysis revealed 10 proteins spots overexpressed after training (Figure 1).

Finally, these proteins correspond to carbonic anhydrase III, beta enolase, creatine kinase, ATP synthase beta subunit, fructose-bisphosphate Aldolase A, Glyceraldehyde-3-phosphate dehydrogenase, triosephosphate isomerase, pyruvate kinase, adenylate kinase, L-lactate dehydrogenase A chain (Table 2). Five proteins corresponding to glycolytic pathway, one to oxidative phosphorylation, one to pyruvate reduction and $\mathrm{NAD}^{+}$regeneration and two proteins have the function to transfer high energy phosphates.

Table 1. Anthropometric and metabolic characteristics baseline and post-training.

\begin{tabular}{ccc}
\hline & Baseline $(\mathrm{n}=4)$ & Post-training $(\mathrm{n}=4)$ \\
\hline Age (years) & $16.1(15-17)$ & $16.3(15-17)$ \\
Weight $(\mathrm{Kg})^{*}$ & $98.6(82.7-130.4)$ & $94.4(79.2-129.3)$ \\
BMI $\left(\mathrm{Kg} / \mathrm{m}^{2}\right)^{*}$ & $33.8(28.2-42.1)$ & $32.4(27.1-41.7)$ \\
Waist circumference $(\mathrm{cm})^{*}$ & $111.5(100-131)$ & $103.3(90.4-127.5)$ \\
Body fat (\%) & $25.9(20.1-36.2)$ & $25.0(13.4-31.0)$ \\
Glucose $(\mathrm{mg} / \mathrm{dl})^{*}$ & $101(89-107)$ & $82.4(76.3-88.5)$ \\
Total cholesterol (mg/dl) & $138(109-171)$ \\
HDL-C (mg/dl) & $152(120-185)$ & $32.4(28.4-41.6)$ \\
LDL (mg/dl) & $36.7(29.4-46.7)$ & $87(61.4-115.2)$ \\
Insulin (microUI/dl) & $78(46.5-119.5)$ & $33.6(15.2-73)$ \\
\hline
\end{tabular}

Data are expressed as mean (min-max). ${ }^{*} \mathrm{p}<0.05$ Baseline Vs Post-training.

Table 2. Proteins identified differentially increase in skeletal muscle after aerobic training in obese adolescents.

\begin{tabular}{cccc} 
No & Accession number & Gene name & \multicolumn{1}{c}{ Protein name } \\
\hline 1 & P00568 & AK1 & Adenylate kinase isoenzyme 1 \\
2 & P60174 & TPI1 & Triosephosphate isomerase 1 \\
3 & P07451 & CA3 & Carbonic anhydrase 3 \\
4 & P00338 & LDHA & L-lactate dehydrogenase A chain \\
5 & P04406 & GAPDH & 36.7 \\
6 & P04075 & ALDOA & Glyceraldehyde-3-phosphate dehydrogenase \\
7 & P06732 & CKM & Fructose-bisphosphate aldolase A \\
8 & P13929 & ENO3 & Creatine kinase M-type \\
9 & P14618 & PKM & Beta-enolase \\
10 & P06576 & ATP5B & Pyruvate kinase muscle isozyme \\
\hline
\end{tabular}

Accession numbers correspond to UNIPROT database. 

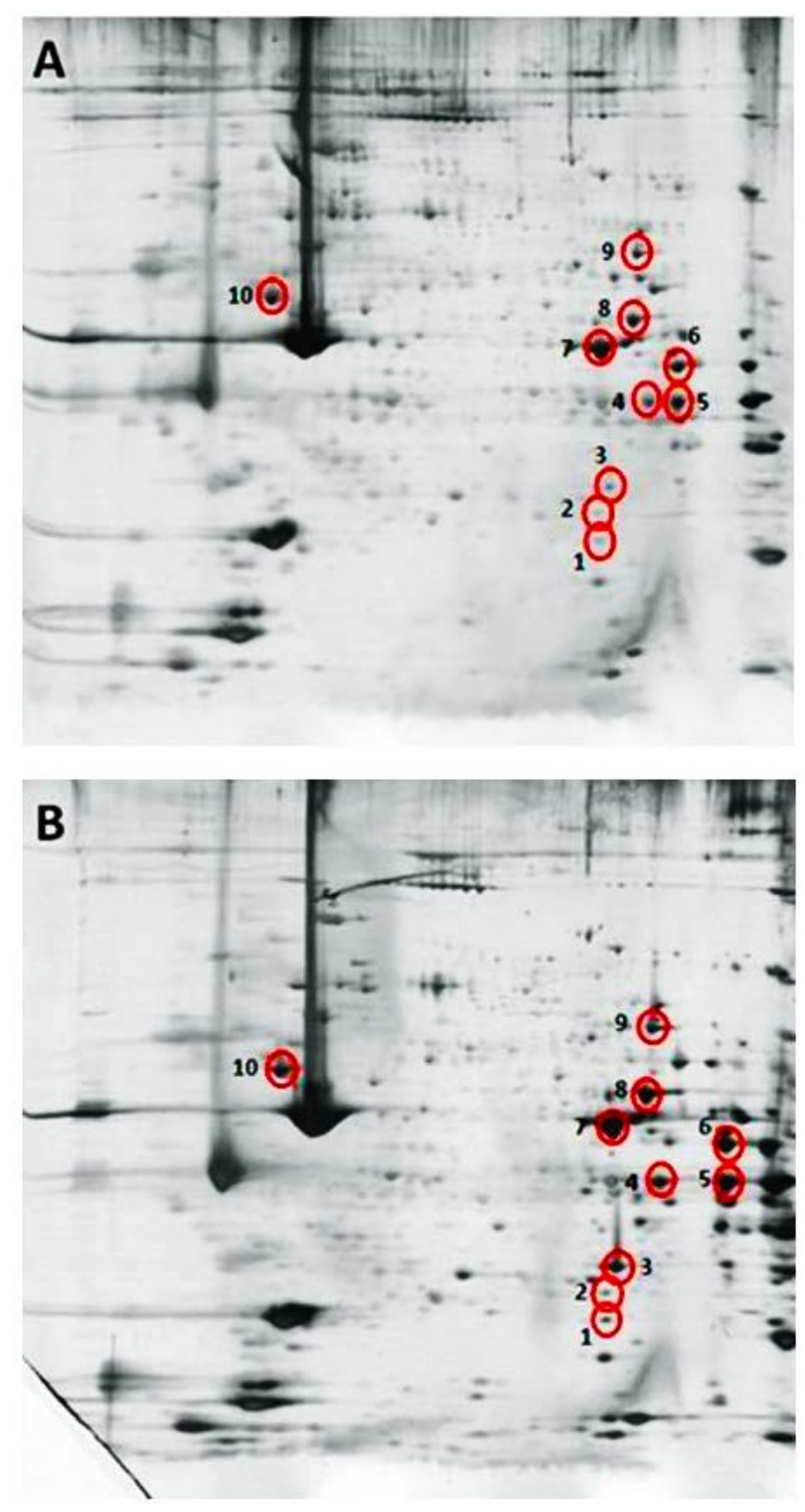

Figure 1. Two-dimensional gels analysis of the skeletal muscle proteins. Proteins were separated by IEF in the first dimension and by size in the second dimension. Spots found with differential expression are marked with numbers.

As shown in Figure 2(A), in order to find relevant proteins among the multiple identifications obtained by proteomic analysis, we subjected the list of the 10 different proteins from Table 2 to bioinformatics analysis in the STRING database. Five proteins were involved in glycolysis pathway (GOTERM_BP_FAT $P=1.56 \mathrm{E}-6)$ (Figure 2(B)).

In order to provide a more comprehensive view of the interactions, ten additional interacting proteins were added. The ten adhered proteins, which interact or are co-expressed with our over-expressed proteins are in Figure 3. Further analysis of the biological meaning of the studied proteins was carried out using the DAVID database. As seen in Figure 3(A), it was found that seven proteins belonging to glycolysis pathway (GOTERM_ BP_FAT $P=3.43 \mathrm{E}-5$ ) and six proteins (Figure 3(B)) are also involved in the biological process of oxidative phosphorylation (GOTERM_BP_FAT $P=4.33 \mathrm{E}-4$ ). Additionally, we found the ubiquitin c protein, which seems to be an important node into the network, by its interaction with several proteins (Figure 3). Ubiquitin c protein may be an activator of protein kinases and participates in some signaling process [21]. 


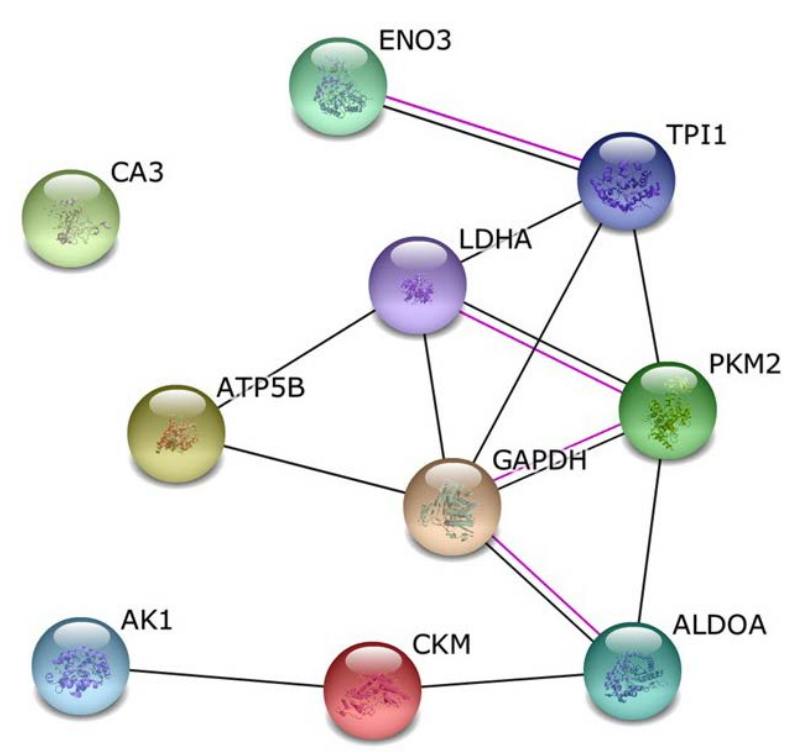

(A)

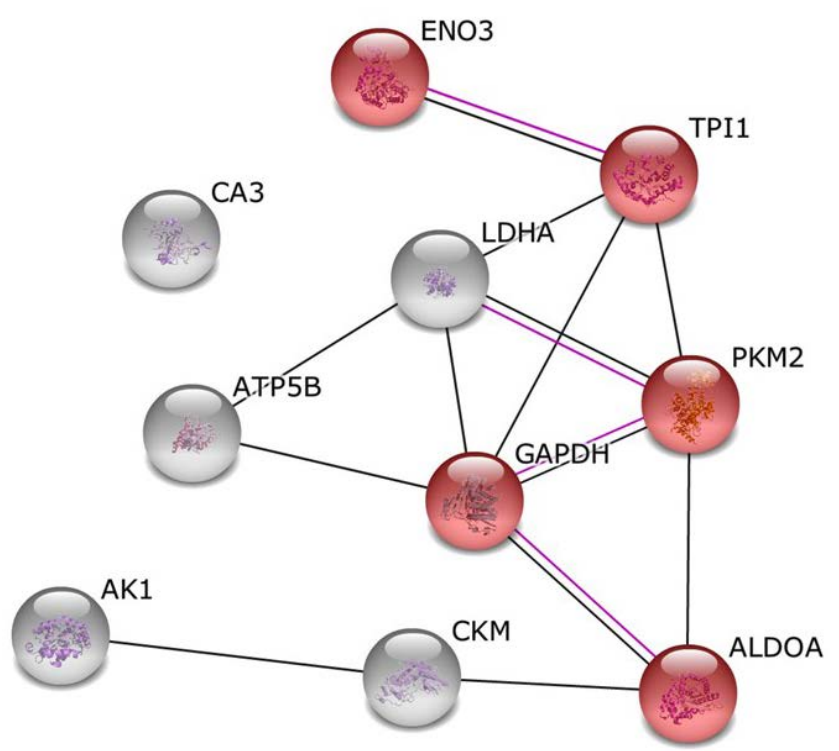

(B)

Figure 2. Bioinformatics analysis by String. The list of identified protein was subjected to String analysis to reveal their functional interactions (A). Each node represents a protein, and each edge represents an interaction. The original graphic output was colored in red to fit the proteins, according to their classification under the gene ontology descriptors "Biological Process: glycolysis pathway" (B) as revealed by the DAVID annotation system.

\section{Discussion}

The main finding of the present study was the increased expression of 10 proteins involved in metabolic aerobic and anaerobic pathways in the vastus lateralis muscle of obese adolescents after 12 weeks of aerobic training, controlling for diet.

Hody et al. have reported the increase of Glyceraldehyde-3-phosphate dehydrogenase, triosephos-phate isomerase, pyruvate kinase, adenylate kinase, Fructose-bisphosphate Aldolase A and L-lactate dehydrogenase A chain, but don't report carbonic anhydrase III, beta enolase, creatine kinase, pyruvate kinase nor ATP synthase 
subunit beta [22]; that difference in results could be due to the stimuli that subjects were exposed to, Hody et al. focused their test on the effects of eccentric training after 6 weeks while the present study considered 12 weeks of aerobic training.

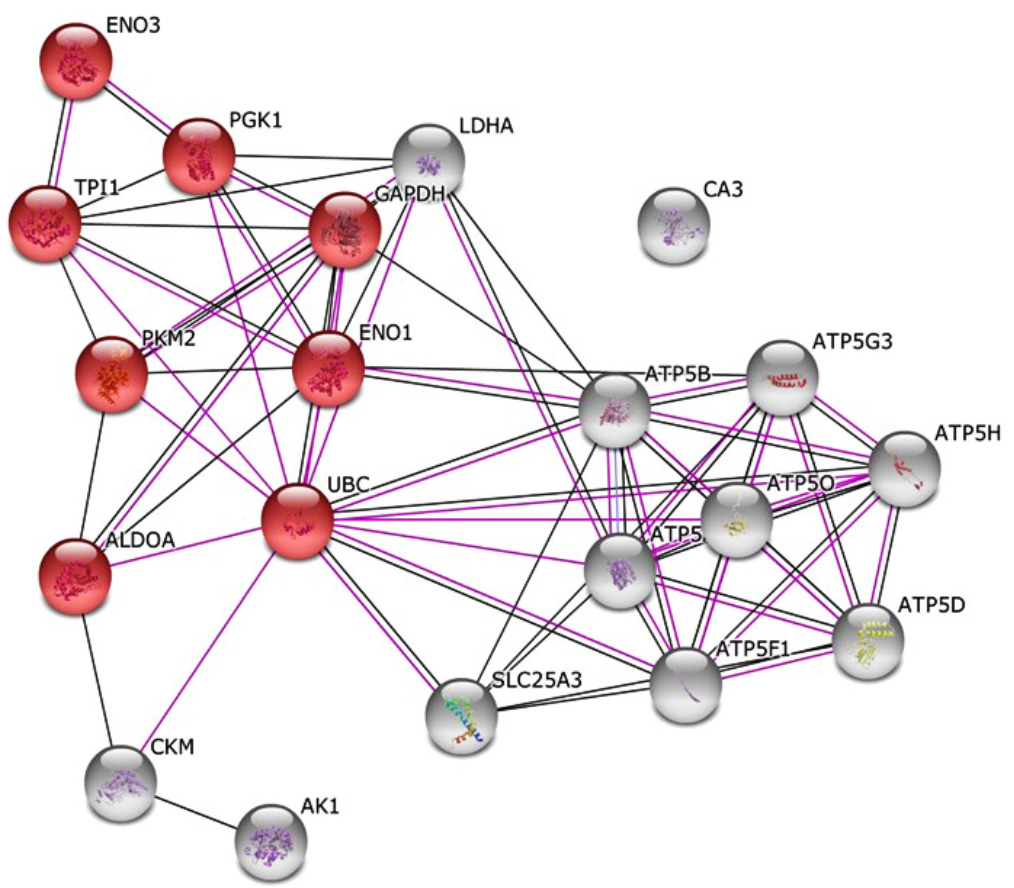

(A)

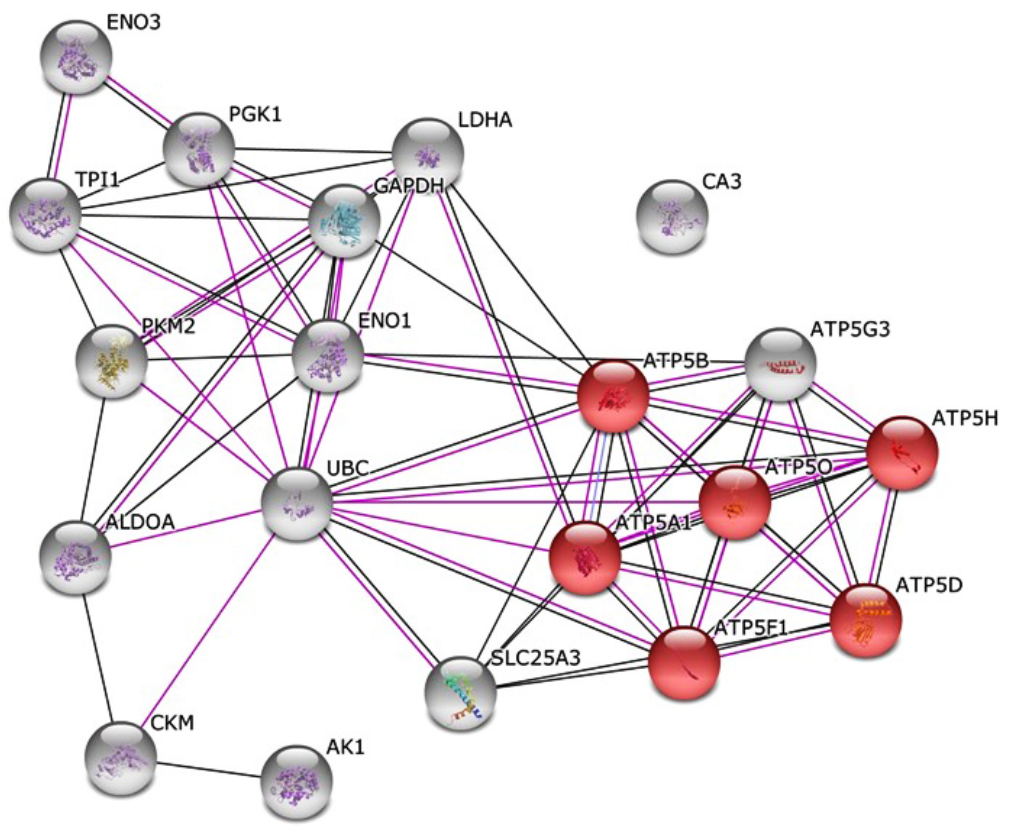

(B)

Figure 3. Bioinformatics analysis by String. Ten additional interacting proteins were added to the String analysis to provide a more comprehensive view of the interactions. The original graphic output was colored in red to fit the proteins, according to their classification under the gene ontology descriptors "Biological Process: glycolysis pathway (A) and oxidative phosphorylation process (B)” as revealed by the DAVID annotation system. 
Similar to other studies [23]-[25] the time course of exercise training induced an increase in protein expression. However this is the first study that shows both changes in proteomics, and improvement in anthropometric and biochemical variables. Protein changes involved in aerobic and anaerobic energy production could make the organism more efficient at burning lipids and carbohydrates.

It also explains the decrease in insulin (44\%), total cholesterol (12\%) and glucose (20\%), as well as the phenotypic expression decreased weight (4.3\%) and waist circumference (8\%).

Importantly, Hittel et al. found an increase in adenylate kinase 1 (AK1), Glyceraldehyde-3 phosphate dehydrogenase (GAPDH), and aldolase A in rectus abdominus muscle from obese/overweight and morbidly obese women relative to lean control subjects [13]. In our study, exercise increased the same proteins and other glycolytic enzymes such as triose phosphate isomerase, pyruvate kinase, L-lactate dehydrogenase A chain, beta enolase, creatine kinase and pyruvate kinase. This increase in glycolytic enzyme could explain the higher efficiency of burning carbohydrates as a beneficial effect of exercise in overweight adolescents.

Additionally, we found that exercise increased adenylate kinase 1 and creatine kinase, which also regulates energy metabolism in muscle [26]. Special attention must be given to the fact of creatine kinase improvement, because it plays a central role in energy transduction in tissues with large, fluctuating energy demands, such as skeletal muscle [27]. The increase of AK1 is representative of an increase in the muscle mitochondrial function with beneficial changes in lipid and carbohydrate metabolism which tend to decrease the weight and waist circumference in adolescents after aerobic training.

Another possible explanation is that carbonic anhydrase III increase may contribute to dissipate muscular fatigue after exercise [25], and maybe improve the adherence to exercise.

When we explored the protein interactions, several ATP synthase subunits were found, which interact or co-express with ATP synthase subunit beta. With regard to ATP synthesis and mitochondrial metabolism, down-regulation of ATP synthase has been reported in skeletal muscle of patients with type 2 diabetes, ad more creatine kinase B [28]. On the other hand, endurance training up-regulates ATP synthase subunit b protein levels in soleus muscle of rats [29]. Thus, a sedentary lifestyle and reduced amounts of oxidative type 1 fibers in overweight subjects [30] might play a role in the altered levels of ATP synthase subunit b observed in our study, which increase with aerobic training. These findings are consistent with a poor reliance on lipid oxidation in the fasting state in muscles of overweight subjects, which changed to a predominant reliance on lipid oxidation in muscles of subjects with aerobic training.

With regard to Ubiquitin c protein as an important node of interaction with the increased proteins after aerobic training and the new found proteins in the network, the linkage type of the ubiquitin chain determines whether a modified protein is either degraded by the proteasome or serves to attract proteins to initiate signaling cascades, or be internalized [21]. These results support the hypothesis that Ub chains have multiple non-degradative roles in cell signaling [31]. There are no prior reports that ubiquitin c protein functions to maintain the glycolytic enzymes bound in skeletal muscle, however our study suggests it as a probable mechanism to explain a higher efficiency in glucose consumption after aerobic training in order to improve metabolic and anthropometric parameters obtained with exercise.

\section{Conclusion}

These proteomic findings suggest that obese adolescents change their phenotype BMI, waist circumference, insulin levels and serum glucose after aerobic exercise through an improved protein expression pattern that especially aids glucose metabolism and increases oxidative phosphorylation, probably due to the ubiquitin c protein that maintains the glycolytic enzymes bound within skeletal muscle, thereby obtaining, a non-degradative role in cell signaling. These proteins play a central role in energy transduction in tissues with large, fluctuating energy demands, such as skeletal muscle.

\section{Acknowledgements}

This study was supported by Universidad de Guanajuato (000119/09) and PROMEP (103-5/08/3252). KVO and JMGF hold a fellowship from CONACYT at the time of writing. The authors acknowledge the Office of Research and Postgraduate Support (Dirección de Apoyo a la Investigación y Posgrado, DAIP) of the University of Guanajuato for the editing of the English-language version of this paper. 


\section{References}

[1] Weinstein, A.R., Sesso, H.D., Lee, I.M., Cook, N.R., Manson, J.E., Buring, J.E. and Gaziano, J.M. (2004) Relationship of Physical Activity vs Body Mass Index with Type 2 Diabetes in Women. The Journal of the American Medical Association, 292, 1188-1194. http://dx.doi.org/10.1001/jama.292.10.1188

[2] Civitarese, A.E. and Ravussin, E. (2008) Mitochondrial Energetics and Insulin Resistance. Endocrinology, 149, 950954. http://dx.doi.org/10.1210/en.2007-1444

[3] Winder, W.W. and Hardie, D.G. (1999) AMP-Activated Protein Kinase, a Metabolic Master Switch: Possible Roles in Type 2 Diabetes. The American Journal of Physiology, 277, E1-10.

[4] Short, K.R., Vittone, J.L., Bigelow, M.L., Proctor, D.N., Rizza, R.A., Coenen-Schimke, J.M. and Nair, K.S. (2003) Impact of Aerobic Exercise Training on Age-Related Changes in Insulin Sensitivity and Muscle Oxidative Capacity. Diabetes, 52, 1888-1896. http://dx.doi.org/10.2337/diabetes.52.8.1888

[5] Lee, S., Kuk, J.L., Davidson, L.E., Hudson, R., Kilpatrick, K., Graham, T.E. and Ross, R. (2005) Exercise without Weight Loss Is an Effective Strategy for Obesity Reduction in Obese Individuals with and without Type 2 Diabetes. Journal of Applied Physiology, 99, 1220-1225. http://dx.doi.org/10.1152/japplphysiol.00053.2005

[6] Ross, R., Janssen, I., Dawson, J., Kungl, A.M., Kuk, J.L., Wong, S.L., Nguyen-Duy, T.B., Lee, S., Kilpatrick, K. and Hudson, R. (2004) Exercise-Induced Reduction in Obesity and Insulin Resistance in Women: A Randomized Controlled Trial. Obesity Research, 12, 789-798. http://dx.doi.org/10.1038/oby.2004.95

[7] Ferguson, M.A., Gutin, B., Le, N.A., Karp, W., Litaker, M., Humphries, M., Okuyama, T., Riggs, S. and Owens, S. (1999) Effects of Exercise Training and Its Cessation on Components of the insulin Resistance Syndrome in Obese Children. International Journal of Obesity and Related Metabolic Disorders, 23, 889-895. http://dx.doi.org/10.1038/sj.ijo.0800968

[8] Macias-Cervantes, M.H., Malacara, J.M., Garay-Sevilla, M.E. and Diaz-Cisneros, F.J. (2009) Effect of Recreational Physical Activity on Insulin Levels in Mexican/Hispanic Children. European Journal of Pediatrics, 168, 1195-1202. http://dx.doi.org/10.1007/s00431-008-0907-7

[9] Wojtaszewski, J.F., Jorgensen, S.B., Frosig, C., MacDonald, C., Birk, J.B. and Richter, E.A. (2003) Insulin Signalling: Effects of Prior Exercise. Acta Physiologica Scandinavica, 178, 321-328. http://dx.doi.org/10.1046/j.1365-201X.2003.01151.x

[10] LeBlanc, P.J., Peters, S.J., Tunstall, R.J., Cameron-Smith, D. and Heigenhauser, G.J. (2004) Effects of Aerobic Training on Pyruvate Dehydrogenase and Pyruvate Dehydrogenase Kinase in Human Skeletal Muscle. The Journal of Physiology, 557, 559-570. http://dx.doi.org/10.1113/jphysiol.2003.058263

[11] Park, H., Kaushik, V.K., Constant, S., Prentki, M., Przybytkowski, E., Ruderman, N.B. and Saha, A.K. (2002) Coordinate Regulation of Malonyl-CoA Decarboxylase, Snglycerol-3-Phosphate Acyltransferase, and Acetyl-CoA Carboxylase by AMP-Activated Protein Kinase in Rat Tissues in Response to Exercise. The Journal of Biological Chemistry, 277, 32571-32577. http://dx.doi.org/10.1074/jbc.M201692200

[12] Green, H.J., Bombardier, E.B., Duhamel, T.A., Holloway, G.P., Tupling, A.R. and Ouyang, J. (2008) Acute Responses in Muscle Mitochondrial and Cytosolic Enzyme Activities during Heavy Intermittent Exercise. Journal of Applied Physiology, 104, 931-937. http://dx.doi.org/10.1152/japplphysiol.01151.2007

[13] Hittel, D.S., Hathout, Y. and Hoffman, E.P. (2007) Proteomics and Systems Biology in Exercise and Sport Sciences Research. Exercise and Sport Sciences Reviews, 35, 5-11. http://dx.doi.org/10.1097/jes.0b013e31802d744a

[14] Cole, T.J., Bellizzi, M.C., Flegal, K.M. and Dietz, W.H. (2000) Establishing a Standard Definition for Child Overweight and Obesity Worldwide: International Survey. BMJ, 320, 1240-1243. http://dx.doi.org/10.1136/bmj.320.7244.1240

[15] Rosas, M., Pastelin, G., Vargas-Alarcon, G., Martinez-Reding, J., Lomeli, C., Mendoza-Gonzalez, C., Lorenzo, J.A., Mendez, A., Franco, M., Sanchez-Lozada, L.G., Verdejo, J., Sanchez, N., Ruiz, R., Ferez-Santander, S.M. and Attie, F., (2008) Clinical Guidelines for Detection, Prevention, Diagnosis and Treatment of Systemic Arterial Hypertension in Mexico. Archivos de Cardiologia de Mexico, 78, S2-5-57.

[16] Jackson, A.S. and Pollock, M.L. (1985) Practical Assessment of Body Composition. Physician Sport Medicine, 13, 76-90.

[17] Pollock, M.L., Bohannon, R.L., Cooper, K.H., Ayres, J.J., Ward, A., White, S.R. and Linnerud, A.C. (1976) A Comparative Analysis of Four Protocols for Maximal Treadmill Stress Testing. American Heart Journal, 92, 39-46. http://dx.doi.org/10.1016/S0002-8703(76)80401-2

[18] Franceschini, A., Szklarczyk, D., Frankild, S., Kuhn, M., Simonovic, M., Roth, A., Lin, J., Minguez, P., Bork, P., von Mering, C. and Jensen, L.J. (2013) STRING v9.1: Protein-Protein Interaction Networks, with Increased Coverage and Integration. Nucleic Acids Research, 41, D808-815. http://dx.doi.org/10.1093/nar/gks1094

[19] Huang da, W., Sherman, B.T. and Lempicki, R.A. (2009) Systematic and Integrative Analysis of Large Gene Lists Us- 
ing DAVID Bioinformatics Resources. Nature Protocols, 4, 44-57.

[20] Huang da, W., Sherman, B.T. and Lempicki, R.A. (2009) Bioinformatics Enrichment Tools: Paths toward the Comprehensive Functional Analysis of Large Gene Lists. Nucleic Acids Research, 37, 1-13. http://dx.doi.org/10.1093/nar/gkn923

[21] Komander, D. (2009) The Emerging Complexity of Protein Ubiquitination. Biochemical Society Transactions, 37, 937953. http://dx.doi.org/10.1042/BST0370937

[22] Hody, S., Leprince, P., Sergeant, K., Renaut, J., Croisier, J.L., Wang, F. and Rogister, B. (2011) Human Muscle Proteome Modifications after Acute or Repeated Eccentric Exercises. Medicine and Science in Sports and Exercise, 43, 2281-2296. http://dx.doi.org/10.1249/MSS.0b013e318222edf3

[23] Egan, B., Dowling, P., O’Connor, P.L., Henry, M., Meleady, P., Zierath, J. R. and O’Gorman, D.J. (2011) 2-D DIGE Analysis of the Mitochondrial Proteome from Human Skeletal Muscle Reveals Time Course-Dependent Remodelling in Response to 14 Consecutive Days of Endurance Exercise Training. Proteomics, 11, 1413-1428. http://dx.doi.org/10.1002/pmic.201000597

[24] Gondin, J., Brocca, L., Bellinzona, E., D’Antona, G., Maffiuletti, N. A., Miotti, D., Pellegrino, M.A. and Bottinelli, R. (2011) Neuromuscular Electrical Stimulation Training Induces Atypical Adaptations of the Human Skeletal Muscle Phenotype: A Functional and Proteomic Analysis. Journal of Applied Physiology, 110, 433-450. http://dx.doi.org/10.1152/japplphysiol.00914.2010

[25] Shang, X., Chen, S., Ren, H., Li, Y. and Huang, H. (2009) Carbonic Anhydrase III: The New Hope for the Elimination of Exercise-Induced Muscle Fatigue. Medical Hypotheses, 72, 427-429. http://dx.doi.org/10.1016/j.mehy.2008.10.027

[26] Janssen, E., Terzic, A., Wieringa, B. and Dzeja, P.P. (2003) Impaired Intracellular Energetic Communication in Muscles from Creatine Kinase and Adenylate Kinase (M-CK/AK1) Double Knock-Out Mice. The Journal of Biological Chemistry, 278, 30441-30449. http://dx.doi.org/10.1074/jbc.M303150200

[27] Dzeja, P.P. and Terzic, A. (2003) Phosphotransfer Networks and Cellular Energetics. The Journal of Experimental Biology, 206, 2039-2047. http://dx.doi.org/10.1242/jeb.00426

[28] Hojlund, K., Wrzesinski, K., Larsen, P.M., Fey, S.J., Roepstorff, P., Handberg, A., Dela, F., Vinten, J., McCormack, J.G., Reynet, C. and Beck-Nielsen, H. (2003) Proteome Analysis Reveals Phosphorylation of ATP Synthase Beta-Subunit in human Skeletal Muscle and Proteins with Potential Roles in Type 2 Diabetes. The Journal of Biological Chemistry, 278, 10436-10442. http://dx.doi.org/10.1074/jbc.M212881200

[29] Gonzalez, B., Hernando, R. and Manso, R. (2000) Stress Proteins of 70 kDa in Chronically Exercised Skeletal Muscle. European Journal of Physiology, 440, 42-49.

[30] Gaster, M., Staehr, P., Beck-Nielsen, H., Schroder, H.D. and Handberg, A. (2001) GLUT4 Is Reduced in Slow Muscle Fibers of Type 2 Diabetic Patients: Is Insulin Resistance in Type 2 Diabetes a Slow, Type 1 Fiber Disease? Diabetes, 50, 1324-1329. http://dx.doi.org/10.2337/diabetes.50.6.1324

[31] Ye, Y., Blaser, G., Horrocks, M.H., Ruedas-Rama, M.J., Ibrahim, S., Zhukov, A.A., Orte, A., Klenerman, D., Jackson, S.E. and Komander, D. (2012) Ubiquitin Chain Conformation Regulates Recognition and Activity of Interacting Proteins. Nature, 492, 266-270. http://dx.doi.org/10.1038/nature11722 